\title{
Modelling the Efficiency of TGARCH Model in Nigeria Inflation Rate
}

\author{
Olayemi, Michael Sunday ${ }^{1 *}$, Olubiyi, Adenike Oluwafunmilola ${ }^{1} \&$ Olajide, Oluwamayowa
}

Opeyimika $^{2}$ and Ajayi, Omolola Felicia ${ }^{2}$

${ }^{1}$ Statistics Department, Ekiti State University, Ado-Ekiti, Nigeria.

${ }^{2}$ Mathematics/Statistics Department, Kogi State Polytechnic, Lokoja, Nigeria.

*Corresponding author: apostlemike2@yahoo.com

In general, volatility is known and referred to as variance and it is a degree of spread of a random variable from its mean value. Two volatility models were considered in this paperwork. Nigeria's inflation rate was modeled by applying the Generalized Autoregressive Conditional Heteroscedasticity (GARCH) and Threshold GARCH models. Symmetric and asymmetric models captured the most commonly stylized facts about the rate of inflation in Nigeria like leverage effects and irregularities in clustering and were studied. These models are $\operatorname{GARCH}(1,1)$ and TGARCH $(1,1)$. This work estimated the comparison of volatility models in term of best fit and forecasting. The result showed that TGARCH $(1,1)$ model outperformed GARCH $(1,1)$ models in term of best fit, because it has the least AIC of 2.590438. We forecasted to see the level of volatility using Theils Inequality Coefficient and the result shows that TGARCH has the highest Theils Inequality Coefficient of 0.065075 which makes the TGARCH model better than the GARCH model in this research. From the initial and modified sample static forecast, it was discovered that the return on inflation is stable and shows that volatility slows towards the end of the month, we can see a downward spiral, which means price reaction to economic crisis led to lower production, lower wages, decreased demand, and still lower prices.

Keywords: forecasting; Inflation; TGARCH; Volatility 


\section{Introduction}

In general, volatility is known and referred to as variance and it is a degree of spread of a random variable from its mean value. The data irregularities study is essential in financial investment. The rate of volatility in a financial market delivers a degree of risk acquaintance to investors on their investments. Inflation is a measurable quantity of proportion at which the current costs over the whole range of goods and services delivered in the economy of a fixed arrangement of customer items and administrations whose cost is assessed all the time, typically month to month or every year. It is the ascent in the overall degree of costs where a unit of money viably purchases short of what it did in earlier periods. It is typically communicated as a rate; inflation, therefore, demonstrates an abatement in the estimation of cash communicated as far as the measure of goods or services that one unit of cash can purchase of a country's cash.

The aim of this paper is to model the efficiency of threshold generalized autoregressive conditional heteroscedasticity (TGARCH) in the Nigerian inflation rate by comparing the TGARCH model with the generalized autoregressive conditional heteroscedasticity $(\mathrm{GARCH})$ model by using various selection criterion. Also, to forecast for the model using initial and modified sample static forecast.

This section gives an overview of related literature on the different models that can be applied in handling volatility problems in any financial investments and other aspects of the Nigerian economy. Bollerslev (1990) introduces a generalized ARCH (GARCH) process that allows a more manageable lag structure. The ARCH/GARCH literature had recently focused on analyzing the volatility of highfrequency data and their benefits (Engle, 2002).

Morakage and Nimal (2015) examined "the volatility behavior of Colombo stock exchange with advanced econometric models, GARCH, EGARCH, and TGARCH models were used to capture the complex volatility features and he observed that volatility clustering and leverage effect exist in the Colombo stock exchange. Also, they discovered that negative stock creates more volatility compared to a positive stock generated in the market. EGARCH model assuming student $\mathrm{t}$ distribution function was discovered to be more suitable in explaining the volatility in the Colombo stock exchange with the aid of Akaike and Schwarz information criteria".

Dana (2016) applied ARCH, GARCH, and EGARCH to investigate the behavior of stock return volatility for the Amman Stock Exchange (ASE) covering the period from $1^{\text {st }}$ of January 2005 through $31^{\text {st }}$ of December 2014. The results suggested that the symmetric models can capture features of ASE, and offer more suggestion for both volatility clustering and leptokurtic, meanwhile EGARCH shows no backing for the existence of leverage effect in the stock returns at Amman Stock Exchange. This research, however, is not limited to the GARCH family only but combines both the GARCH and SARIMA models in modeling and forecasting volatility of the financial investment.

Savadatti (2018) analyzed the volatility pattern of the Bombay Stock Exchange (BSE) using symmetric and asymmetric GARCH models based on the daily return series of the $\mathrm{S}$ and P BSE all-cap index covering 2005 to 2018 . The result shows evidence for the presence of leverage effect in the daily 
return series. Shveta and Teena (2019) carried out research on "modeling the volatility of banking sectors of a national stock exchange. He discovered that both the composite Bank sector (Bank) and PSU bank sector (PSU) showed volatility clustering, significant persistence, and leverage effect but the PSU bank sector is more prone to negative news and its returns are more volatile, composite Bank sector is less prone to negative shocks due to inclusion of private banks". He also discovered that the volatility shocks take time to die out in both sectors and also the volatility of both sectors is explosive with the help of the EGARCH model with student t-distribution. Meanwhile, ARCH and GARCH coefficients of both sectors are positive and significant indicating the presence of volatility.

Ismail. O et al (2017) in their study looked into the comparison of the performance of GARCHType models in modeling inflation volatility in Nigeria for the period of 260 months. In their paper, they provided two main inventions: "they analyze the inflation rate of two pronounced consumer prices indices namely headline and core consumer price indices using the Augmented Dickey-Fuller breakpoint test which allow for structural breaks in the data series; and the method is modified to include both symmetric and asymmetric volatility models. Their empirical examination observes evidence of volatility persistence in the consumer price indices, but the only headline is consistent with leverage effects. They concluded that applying a one-model fits-all approach as well as discarding the role of structural breaks for inflation rate volatility in Nigeria will yield misleading and invalid policy prescriptions".

Mohammad Ali Moradi (2006) in his paper "investigates the relationship between inflation and inflation uncertainty using the Iranian data through March 1959 - December 2005. GARCH models were used to examine this relationship. Granger methods were employed to provide statistical evidence for the relationship between average inflation and inflation uncertainty". Furthermore, "the findings of bi-directional causality supports the Cukierman and Meltzer model. Using the standard TGARCH models, the presence of asymmetry is found in the conditional variance of annualized inflation, and finally, the evidence of long memory exists in the conditional variance of annualized inflation".

Mulukalapally (2017) completed an examination on demonstrating and gauging the monetary instability of day by day returns of India's financial exchange from September 172007 to December 30, 2016. They applied GARCH family models to research the conduct of stock return unpredictability for India's financial exchange. The outcome shows that there is a nearness of unpredictability bunching, proof of hilter kilter, and influence impact on instability and non-presence of hazard premium in the Indian financial exchange.

Pradipta and Padma (2016) concentrated on three perspectives - volatility in the stock markets across the globe by application of GARCH family models, investigation of ARMA structures, and a correlation of symmetric and asymmetric volatility. In the most recent decade or something like that, financial specialists from created nations are for the most part concentrating on the developing financial aspects as their speculation openings. They partner a decent measure of hazard premium with these 
nations most definitely with their ventures. Ventures drawn from created countries appear to make financial exchanges of developing countries more unstable as these speculations are presented to both silly and discerning variables. Subsequently, it is basic to comprehend the instability conduct of rising financial exchanges over some undefined time frame and to contemplate the near examination of the unpredictability practices' over these business sectors. This made the analyst return to the subject on instability conduct thinking about the developing markets for this investigation. In this paper, an endeavor was made to evaluate the instability conduct of financial exchanges of 10 developing financial aspects and thus focused on India, China, Indonesia, Sri Lanka, Pakistan, Russia, Brazil, South Korea, Mexico, and Hong Kong. At long last, the analyst's reason that Volatility estimations over the nations are seen as high during the time of worldwide monetary emergency. Hilter kilter data saw as affected all the nations during the time of study and volatility in Pakistan, Srilanka, and Indonesia are generally affected through ongoing data.

Conclusively, this paperwork reviews the diverse models that can be used in handling and forecasting volatility problems.

Related methodologies such as ARCH/GARCH, EGARCH, TGARCH, and others were reviewed. However, in this empirical work, we will be looking at the efficiency of the TGARCH model in dealing with volatility in Nigeria inflation rate that should be able to take care of some of the limitations discovered in the reviewed literature as regards all kinds of volatility problem.

The volatility of Nigerian stock market was modelled using the skewed part of error innovation distribution that is normal, student-t and generalized with the aim of determining the combination of volatility model and the skewed error distribution that best capture the changing aspects in the volatility of the stock market. The parameters of these volatility models at each of the error distribution were estimated using R software. The result indicated that the skewed normal distribution outperformed all other error innovation distribution applied in term of the best of fit. Also, APARCH $(1,1)$ using skewed normal distribution based on the least RMSE gives the best result in term of forecasting evaluation. There was an evidence of volatility clustering and high persistence volatility which specified high level of risk and uncertainties in Nigerian stock market according to Samson et al. (2020).

Timothy et al. (2020) "compared the performance of GARCH models and its extensions using five innovation distributions, normal distribution, Student- $t$ distribution, generalized error distribution, skewed Student- $t$ and skewed generalized error distribution". The model's performances were linked in terms of best fit and forecasting evaluation performance. The asymmetric models (TGARCH $(1,1)$ and E-GARCH $(1,1)$ ) were endorsed as the best model for forecasting the volatility in ETI and Zenith bank stocks correspondingly. 


\section{Materials and Methods}

The time-series data used for modeling volatility in this paper is the monthly inflation rate of all items (percentage) in Nigeria over the study period (January 2003 through May 2020) obtained from the Central Bank of Nigeria (CBN) website.

The volatility models applied in this paper include the GARCH $(1,1)$ and TGARCH $(1,1)$. The conditional variance equations that will be utilized in this paper are the symmetric and lopsided (asymmetric) GARCH models. The ARCH model is as presented below:

$$
\sigma_{t}^{2}=w+\sum_{i=1}^{q} x_{i} u_{t-i}^{2}
$$

where $w \geq 0$ and $x_{i} \geq 0$ for $i=0,1,2, \ldots, q . \sigma_{t}^{2}$ is the variance at time $t, a$ is the constant, $b_{i}$ are the parameters of the ARCH effect and $u_{t-i}^{2}$ is the lagged values of the prediction error squared as $i=$ $0,1,2, \ldots, q$.

"The GARCH method has a wide range of capital markets applications. The model is based on the assumptions that forecast the variance changing in time which depends on the lagged variance of capital assets. An unexpected increase or fall in the returns of an asset at time $t$ will generate an increase in the variability expected in the period to come".

For a univariate series, let the general form of GARCH model is as below:

$$
\sigma_{t}^{2}=w+\sum_{i=1}^{q} x_{i} u_{t-i}^{2}+\sum_{j=1}^{p} y_{j} \sigma_{t-j}^{2}+e_{t}
$$

"where $p$ is the degree of GARCH; $q$ is the degree of the ARCH process; and $\mathrm{e}_{t}$ a random component with the properties of white noise".

The basic and most widespread model is $\operatorname{GARCH}(1,1)$, which can be expressed as:

$$
\sigma_{t}^{2}=w+x u_{t-1}^{2}+y \sigma_{t-1}^{2}+e_{t}
$$

"Such that $\sigma_{t}^{2}, w, x$ and $u_{t-i}^{2}$ is as defined in equation (1), $c$ is the GARCH coefficient and $u_{t-1}^{2}$ represents the one-period lag of the fitted variance from the model. To ascertain a well-defined GARCH $(1,1)$ model, it is required that $x \geq 0$ and $y \geq 0$, while $x+y<1$ suffices for covariance stationarity".

TGARCH model is stated as

$$
h_{t}=\emptyset+\sum_{k=1}^{p} \theta_{k} h_{t-k}+\sum_{i=1}^{q}\left(b_{i}+y_{i} D_{t-i}\right) u_{t-1}^{2}
$$

TGARCH $(1,1)$ can be expressed as;

$$
h_{t}=\emptyset+\theta_{1} h_{t-1}+b_{1} u_{t-1}^{2}+y_{1} u_{t-1}^{2} D_{t-1}
$$

"where $D_{t}$ takes the value of 1 (bad news) for $u_{t}<0$ and 0 otherwise, so 'good news' and 'bad news' have different impact. Good news (positive shock) has an impact of $b_{1}$. While bad news (negative shock) has an impact of $b_{1}+y_{1} "$. 


\section{Results and Discussion}

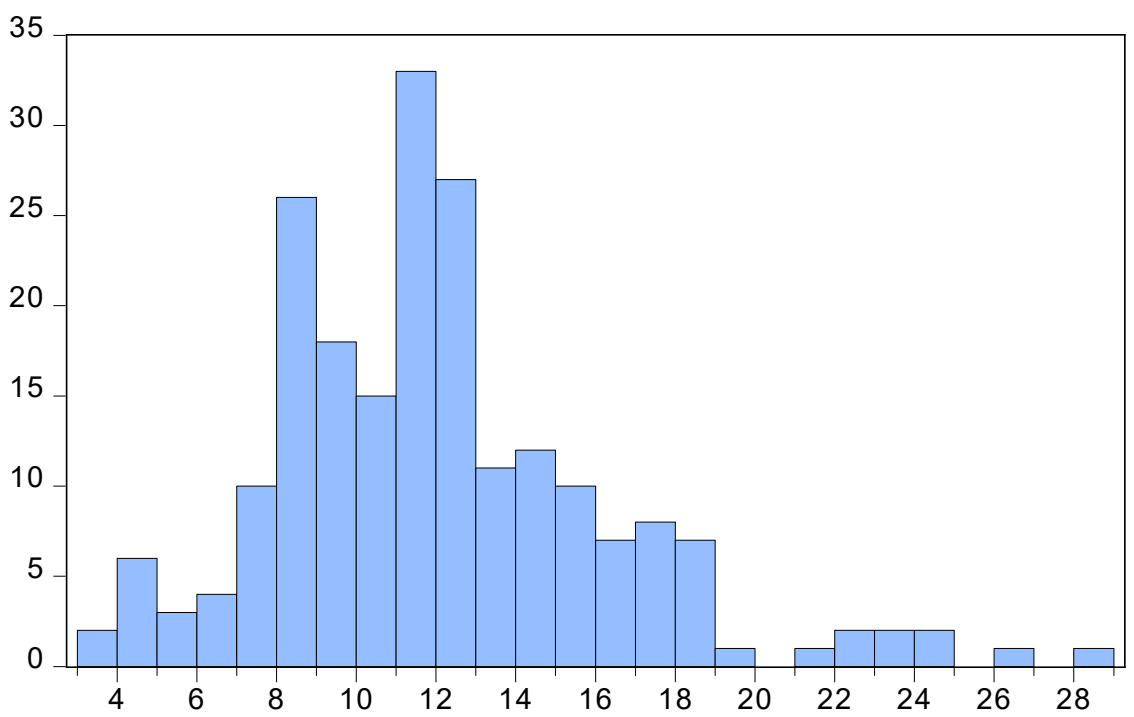

Series: INF

Sample 2003M01 2020M05

Observations 209

Mean

11.96158

Median

11.38000

Maximum

28.20000

Minimum

3.000000

Std. Dev.

4.264771

Skewness

0.910506

Kurtosis

4.501032

Jarque-Bera

Probability

Figure 1: Descriptive statistics of Nigeria Inflation Rate

The Nigeria Inflation Rate has a great difference between its highest and lowest returns. There is high increase in the standard deviation which indicates a high level of variations in the Nigeria Inflation Rate. positive skewness is evident, which implies that the right tail is mostly extreme, which is an indication that Nigeria Inflation Rate has non-symmetric returns. The Nigeria Inflation Rate is leptokurtic or fat-tailed. The Nigeria Inflation Rate series conform with normal distribution and displayed positive skewness as seen in Figure 1 above.

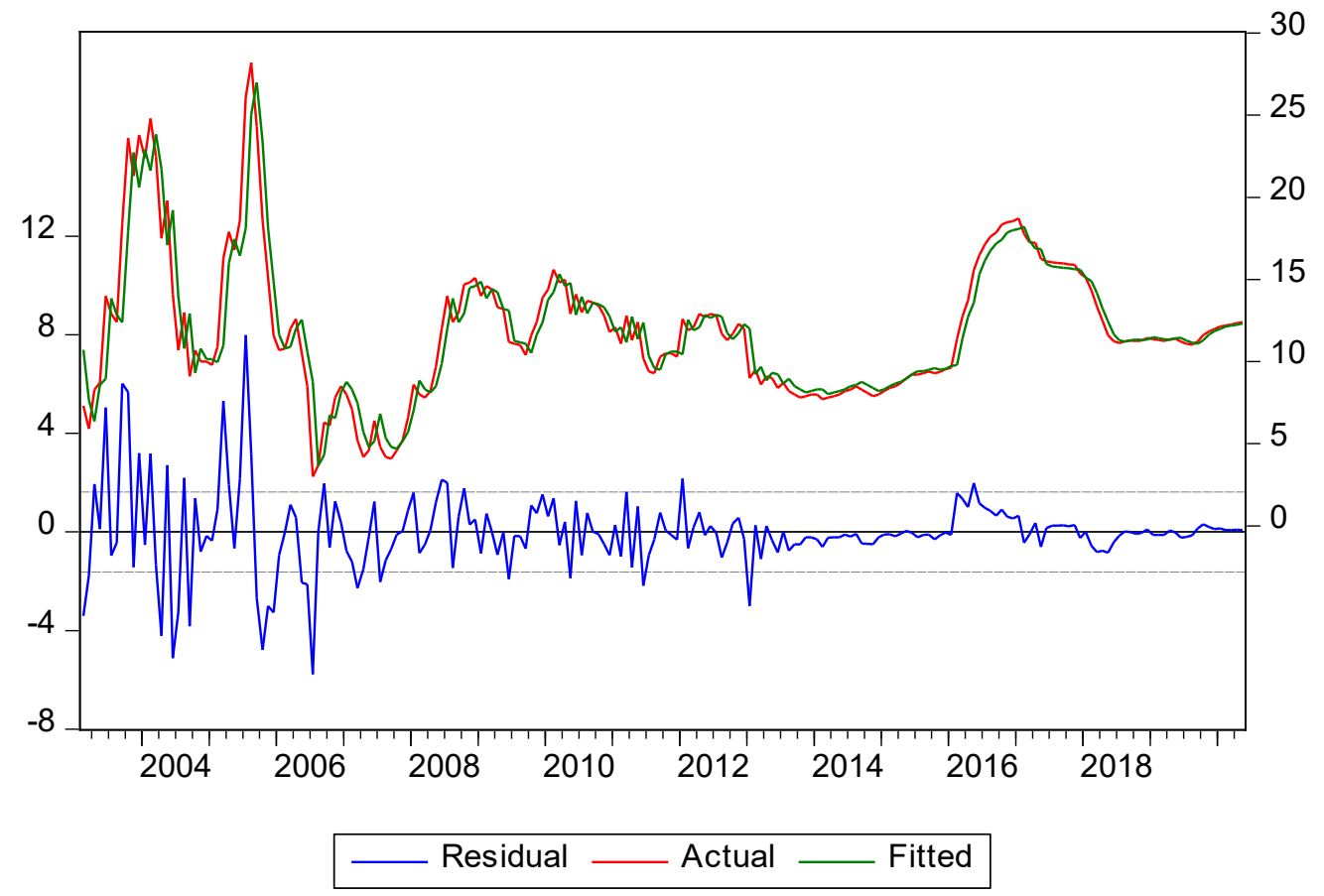

Figure 2: Descriptive statistics of Nigeria inflation rate in percentage 
From the year 2003 to the year 2006, a period of high volatility follows by another period of high volatility for a prolonged period, then, from the year 2006 to the year 2020 a period of low volatility followed by another period of low volatility for a prolonged period. This shows that we can proceed to check the ARCH effect of the Nigeria inflation of all items in percentage.

Table 1: Heteroskedasticity Test: ARCH

\begin{tabular}{|c|c|c|c|c|}
\hline F-statistic & 13.68455 & \multicolumn{2}{|c|}{ Prob. F(1,205) } & 0.0003 \\
\hline $\mathrm{O} * \mathrm{R}$-squared & 12.95337 & \multicolumn{2}{|c|}{ Prob. Chi-Square(1) } & 0.0003 \\
\hline \multicolumn{2}{|l|}{ Test Equation: } & & & \\
\hline \multicolumn{5}{|c|}{ Dependent Variable: RESID ${ }^{\wedge} 2$} \\
\hline \multicolumn{5}{|l|}{ Method: Least Squares } \\
\hline \multicolumn{5}{|c|}{ Modified sample : 2003M03 2020M05 } \\
\hline \multicolumn{4}{|c|}{ Encompassed explanations: 207 subsequent changes } & \\
\hline "Variable" & "Coefficient" & $\begin{array}{l}\text { Standard. } \\
\text { Error }\end{array}$ & test-Statistic & Probability \\
\hline $\mathrm{C}$ & 1.923278 & $\mathrm{z} 0.514522$ & 3.737987 & 0.0002 \\
\hline $\operatorname{RESID}^{\wedge} 2(-1)$ & 0.249273 & 0.067384 & 3.699264 & 0.0003 \\
\hline "R-squared" & 0.062577 & \multicolumn{2}{|c|}{ Mean dependent variable } & 2.580539 \\
\hline "Adjusted R-squared" & 0.058004 & \multicolumn{2}{|c|}{$\begin{array}{l}\text { Standard deviation dependent } \\
\text { variable }\end{array}$} & 7.158017 \\
\hline "S.E. of regression" & 6.947319 & \multicolumn{2}{|l|}{ AIC } & 6.724204 \\
\hline "Sum squared residual" & 9894.375 & \multicolumn{2}{|l|}{$\mathrm{SIC}$} & 6.756404 \\
\hline "Log likelihood" & -693.9551 & \multicolumn{2}{|l|}{ H-Q } & 6.737225 \\
\hline "F-statistic" & 13.68455 & \multicolumn{2}{|c|}{ Durbin-Watson stat } & 2.055227 \\
\hline Probability(F-statistic) & 0.000278 & & & \\
\hline
\end{tabular}

Sample: January, 2003 to May, 2020

Null hypotheses: "there is no ARCH effect vs Alternative hypotheses: there ARCH effect.

Since the p-value is very small less than $5 \%$ significant we, therefore, reject null hypotheses and accept the alternative hypothesis. That is, there is an ARCH effect Also, the F statistic and $\mathrm{O} * R^{2}$ indicate the presence of ARCH in the data. This totally justifies the use of GARCH and TGARCH models. Next, we specify the GARCH $(1,1)$ and TGARCH $(1,1)$ models and carry out the analysis. This analysis was carried out using the e-views software". 
Table 2: GARCH Test with normal Distribution

\begin{tabular}{|c|c|c|c|c|}
\hline \multicolumn{5}{|l|}{ Dependent Variable: INF } \\
\hline \multicolumn{5}{|c|}{ GARCH $=\mathrm{W}+\mathrm{X}^{*} \mathrm{RESID}(-1)^{\wedge} 2+\mathrm{Y}^{*} \mathrm{GARCH}(-1)$} \\
\hline "Variable" & $\begin{array}{l}\text { "Coefficient } \\
"\end{array}$ & Standard. Error & test-Statistic & Probability. \\
\hline $\mathrm{C}$ & 0.470889 & 0.304574 & 1.546055 & 0.1221 \\
\hline \multirow[t]{2}{*}{ INF(-1) } & 0.958506 & 0.025177 & 38.07043 & 0.0000 \\
\hline & \multicolumn{2}{|c|}{ Variance Equation } & & \\
\hline $\mathrm{C}$ & 0.017913 & 0.005815 & 3.080340 & 0.0021 \\
\hline $\operatorname{RESID}(-1)^{\wedge} 2$ & 0.150488 & 0.053990 & 2.787356 & 0.0053 \\
\hline GARCH(-1) & 0.824045 & 0.041033 & 20.08267 & 0.0000 \\
\hline R-squared & 0.854457 & \multicolumn{2}{|c|}{ Mean dependent variable } & 11.96813 \\
\hline "Adjusted R-squared" & 0.853751 & \multicolumn{2}{|c|}{ S.D. dependent variable } & 4.274008 \\
\hline "S.E. of regression" & 1.634490 & \multicolumn{2}{|c|}{ AIC } & 2.921072 \\
\hline "Sum squared residual" & 550.3407 & \multicolumn{2}{|c|}{ SIC } & 3.001302 \\
\hline "Log likelihood" & -298.7915 & \multicolumn{2}{|c|}{ H-Q } & 2.953513 \\
\hline "Durbin-Watson statistic" & \multicolumn{4}{|l|}{1.639455} \\
\hline
\end{tabular}

Sample: January, 2003 to May, 2020

Mean equation:

$$
y_{t}=0.470889+0.958506 y_{t-1}
$$

"Coefficients are positive and statistically significant and Average inflation rate is 0.470889 and it past value significantly predict the current series by $0.9585 "$.

Variance Equation:

$$
\sigma_{t}^{2}=0.017913+0.150488 e_{t-1}^{2}+0.824045 \sigma_{t-1}^{2}+w_{t}
$$

"Coefficients of the constant variance term, the ARCH and GARCH parameters are positive and statistically significant at $1 \%$ level.

This gives the result of the GARCH model. The time varying volatility includes a constant (0.017193) plus its past $\left(0.824045 \sigma_{t-1}^{2}\right)$ and a component which depend on the past error $\left(0.150488 e_{t-1}^{2}\right) "$. 
Table 3: GARCH Test with student's t

\begin{tabular}{|l|l|l|l|l|}
\hline \multicolumn{5}{|l|}{ Dependent Variable: INF } \\
\hline GARCH = W + X*RESID(-1)^2+ Y*GARCH(-1) \\
\hline "Variable" & "Coefficient" & Standard. Error & "z-Statistic" & Probability. \\
\hline C & 0.343916 & 0.109943 & 3.128132 & 0.0018 \\
\hline INF(-1) & 0.971991 & 0.009958 & 97.61203 & 0.0000 \\
\hline & "Variance Equation" & & \\
\hline C & 0.006611 & 0.006192 & 1.067737 & 0.2856 \\
\hline "RESID(-1)^2" & 0.670351 & 0.417022 & 1.607470 & 0.1080 \\
\hline "GARCH(-1)" & 0.656640 & 0.070677 & 9.290746 & 0.0000 \\
\hline "T-DIST. DOF" & 2.754255 & 0.586321 & 4.697524 & 0.0000 \\
\hline "R-squared" & 0.853430 & "Mean dependent var" & 11.96813 \\
\hline "Adjusted R-squared" & 0.852718 & "S.D. dependent var" & 4.274008 \\
\hline S.E. of regression & 1.640248 & "Akaike info criterion" & 2.652500 \\
\hline "Sum squared resid" & 554.2255 & "Schwarz criterion" & 2.748776 \\
\hline "Log likelihood" & -269.8600 & "Hannan-Quinn criter". & 2.691429 \\
\hline $\begin{array}{l}\text { "Durbin-Watson } \\
\text { statistic" }\end{array}$ & 1.650159 & \multicolumn{4}{l}{} \\
\hline
\end{tabular}

Sample: January, 2003 to May, 2020

Mean equation:

$$
y_{t}=0.343916+0.971991 y_{t-1}
$$

"Coefficients are positive and statistically significant and Average inflation rate is 0.343916 and it past value significantly predict the current series by $0.971991 "$.

Variance Equation:

$$
\sigma_{t}^{2}=0.006611+0.670351 u_{t-1}^{2}+0.6566409 \sigma_{t-1}^{2}+w_{t}
$$

Coefficients of the constant variance term, the ARCH and GARCH parameters are positive but only the GARCH that is statistically significant at $1 \%$ level. 
Table 4: TGARCH Test with normal Distribution

\begin{tabular}{|c|c|c|c|c|}
\hline \multicolumn{5}{|l|}{ Dependent Variable: INF } \\
\hline \multicolumn{5}{|c|}{ Method: ML ARCH - Normal distribution (BHHH / EViews legacy) } \\
\hline \multicolumn{5}{|c|}{ Sample (adjusted): 2003M02 2020M05 } \\
\hline \multicolumn{5}{|c|}{$\mathrm{GARCH}=\mathrm{W}+\mathrm{X}^{*} \mathrm{RESID}(-1)^{\wedge} 2+\mathrm{Y}^{*} \operatorname{RESID}(-1)^{\wedge} 2^{*}(\operatorname{RESID}(-1)<0)+\mathrm{Z} * \operatorname{GARCH}(-1)$} \\
\hline Variable & Coefficient & Std. Error & z-Statistic & Prob. \\
\hline $\mathrm{C}$ & 0.276715 & 0.169024 & 1.637137 & 0.1016 \\
\hline \multirow[t]{2}{*}{ INF(-1) } & 0.977265 & 0.014839 & 65.85997 & 0.0000 \\
\hline & \multicolumn{2}{|c|}{ "Variance Equation" } & & \\
\hline $\mathrm{C}$ & 0.015328 & 0.003603 & 4.254570 & 0.0000 \\
\hline $\operatorname{RESID}(-1)^{\wedge} 2$ & 0.187037 & 0.022543 & 8.296906 & 0.0000 \\
\hline $\operatorname{RESID}(-1)^{\wedge} 2 *(\operatorname{RESID}(-1)<0)$ & -0.224959 & 0.041094 & -5.474307 & 0.0000 \\
\hline GARCH(-1) & 0.881418 & 0.020509 & 42.97787 & 0.0000 \\
\hline "R-squared" & 0.852903 & \multicolumn{2}{|c|}{ "Mean dependent var" } & 11.96813 \\
\hline "Adjusted R-squared" & 0.852189 & \multicolumn{2}{|c|}{ "S.D. dependent var" } & 4.274008 \\
\hline "S.E. of regression" & 1.643192 & \multicolumn{2}{|c|}{ "Akaike info criterion" } & 2.832548 \\
\hline "Sum squared resid" & 556.2164 & \multicolumn{2}{|c|}{ "Schwarz criterion" } & 2.928823 \\
\hline "Log likelihood" & -288.5850 & \multicolumn{2}{|c|}{ "Hannan-Quinn criter". } & 2.871477 \\
\hline "Durbin-Watson stat" & \multicolumn{4}{|l|}{1.653004} \\
\hline
\end{tabular}

Sample: January, 2003 to May, 2020

The conditional variance for a TGARCH $(1,1)$ model is stated as

$$
h_{t}=\varnothing+\theta_{1} h_{t-1}+b_{1} u_{t-1}^{2}+y_{1} u_{t-1}^{2} D_{t-1}
$$

"where $D_{t}$ takes the value of 1 (bad news) for $u_{t}<0$ and 0 otherwise, so 'good news' and 'bad news' have different impact. Good news (positive shock) has an impact of $b_{1}$. While bad news (negative shock) has an impact of $b_{1}+y_{1}$.

$y$ is known as the asymmetry or leverage term. $y>0$ is asymmetry, while $y=0$ is symmetry (model collapses to the standard GARCH). IF y is significant and positive, negative shocks will have large effects on $h_{t}$ than positive shocks".

TGARCH models can be extended to higher order specifications by including more lagged terms as follows. Therefore, the TGARCH (p, q) model is stated as

$$
h_{t}=\varnothing+\sum_{k=1}^{p} \theta_{k} h_{t-k}+\sum_{i=1}^{q}\left(b_{i}+y_{i} D_{t-i}\right) u_{t-1}^{2}
$$

"Positive shock: the estimate of the time varying volatility is given as:

$$
\widehat{h_{t}}=0.015328+0.881418 \widehat{h_{t-1}}+0.187037{\widehat{u^{2}}}_{t-1}
$$


Negative shock: the estimate of the time varying volatility is given as

$$
\widehat{h_{t}}=0.015328+0.881418 \widehat{h_{t-1}}+(0.187037-0.224959) \widehat{u^{2}}{ }_{t-1}
$$

The difference between good and bad news on the inflation rate is -0.224959 which is the coefficient of the asymmetric term, $y$.

Conclusion: the modelling of information, news or events are very significant determinants of inflation volatility".

Note: "Bad news have larger effects than good news" if $b_{1}+Y>b_{1}$.

Table 5: TGARCH Test with student's t

\begin{tabular}{|c|c|c|c|c|}
\hline \multicolumn{5}{|l|}{ Dependent Variable: INF } \\
\hline \multicolumn{5}{|c|}{ Method: ML ARCH - Student's t distribution (BHHH / EViews legacy) } \\
\hline \multicolumn{5}{|c|}{ Sample (adjusted): 2003M02 2020M05 } \\
\hline \multicolumn{5}{|c|}{ GARCH $=\mathrm{W}+\mathrm{X} * \mathrm{RESID}(-1)^{\wedge} 2+\mathrm{Y}^{*} \operatorname{RESID}(-1)^{\wedge} 2^{*}(\operatorname{RESID}(-1)<0)+\mathrm{Z} * \operatorname{GARCH}(-1)$} \\
\hline Variable & Coefficient & Std. Error & z-Statistic & Prob. \\
\hline $\mathrm{C}$ & 0.338590 & 0.117325 & 2.885923 & 0.0039 \\
\hline \multirow[t]{2}{*}{$\operatorname{INF}(-1)$} & 0.972472 & 0.011459 & 84.86784 & 0.0000 \\
\hline & \multicolumn{2}{|c|}{ Variance Equation } & & \\
\hline $\mathrm{C}$ & 0.001549 & 0.001900 & 0.815371 & 0.4149 \\
\hline "RESID $(-1)^{\wedge} 2 "$ & 0.301551 & 0.106541 & 2.830377 & 0.0046 \\
\hline "RESID $(-1)^{\wedge} 2 *(\operatorname{RESID}(-1)<0) "$ & -0.344508 & 0.109656 & -3.141712 & 0.0017 \\
\hline "GARCH(-1)" & 0.889426 & 0.027101 & 32.81861 & 0.0000 \\
\hline "T-DIST. DOF" & 3.660679 & 0.914386 & 4.003428 & 0.0001 \\
\hline R-squared & 0.853384 & \multicolumn{2}{|c|}{ Mean dependent var } & 11.96813 \\
\hline Adjusted R-squared & 0.852672 & \multicolumn{2}{|c|}{ S.D. dependent var } & 4.274008 \\
\hline S.E. of regression & 1.640504 & \multicolumn{2}{|c|}{ Akaike info criterion } & 2.590438 \\
\hline Sum squared resid & 554.3981 & \multicolumn{2}{|c|}{ Schwarz criterion } & 2.702759 \\
\hline Log likelihood & -262.4056 & \multicolumn{2}{|c|}{ Hannan-Quinn criter. } & 2.635855 \\
\hline Durbin-Watson stat & \multicolumn{4}{|l|}{1.650443} \\
\hline
\end{tabular}

Sample: January, 2003 to May, 2020

The conditional variance for a TGARCH $(1,1)$ model is stated as

$$
h_{t}=\varnothing+\theta_{1} h_{t-1}+b_{1} u_{t-1}^{2}+y_{1} u_{t-1}^{2} D_{t-1}
$$

"where $D_{t}$ takes the value of 1 (bad news) for $u_{t}<0$ and 0 otherwise, so 'good news' and 'bad news' have different impact. Good news (positive shock) has an impact of $b_{1}$. While bad news (negative shock) has an impact of $b_{1}+y_{1}$. 
$y$ is known as the asymmetry or leverage term. $y>0$ is asymmetry, while $y=0$ is symmetry (model collapses to the standard GARCH). If $\mathrm{y}$ is significant and positive, negative shocks will have large effects on $h_{t}$ than positive shocks".

TGARCH models can be extended to higher order specifications by including more lagged terms as follows. Therefore, the TGARCH $(p, q)$ model is stated as

$$
h_{t}=\varnothing+\sum_{k=1}^{p} \theta_{k} h_{t-k}+\sum_{i=1}^{q}\left(b_{i}+y_{i} D_{t-i}\right) u_{t-i}^{2}
$$

"The estimate of the time varying volatility is given as:

$$
\widehat{h_{t}}=0.001549+0.889426 \widehat{h_{t-1}}+0.301551 \widehat{u}_{t-1}^{2}
$$

and the estimate of the time varying volatility is given as

$$
\widehat{h_{t}}=0.001549+0.889426 \widehat{h_{t-1}}+(0.301551-0.344508) \widehat{u^{2}}{ }_{t-1}
$$

The difference between good and bad news on the inflation rate is -0.344508 which is the coefficient of the asymmetric term, $y$. The modelling of information, news or events are very significant determinants of inflation volatility. Bad news has larger effects than good news" if $b_{1}+y>b_{1}$.

Since, $b_{1}+y<b_{1}$, we conclude that there is positive shock in the result obtained.
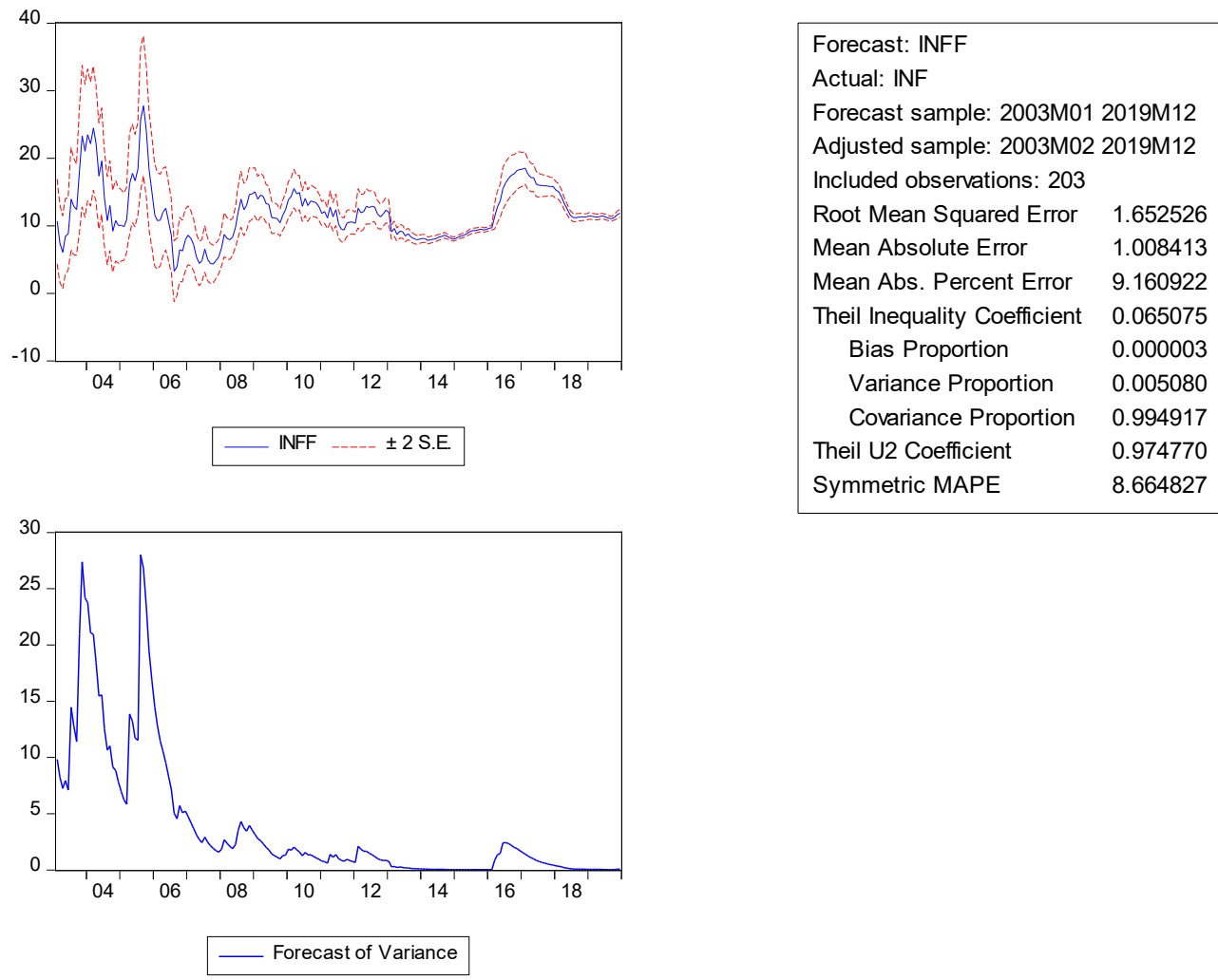

Figure 3: Initial Sample Static forecast (TGARCH)

The return on inflation rate is stable but shows intense volatility. 


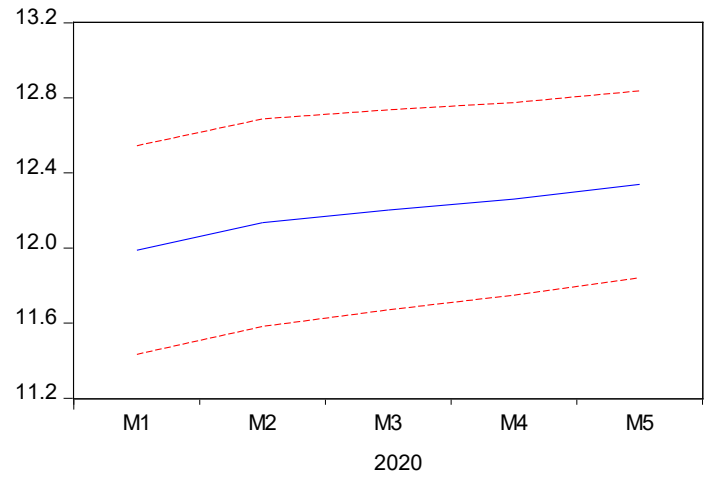

\begin{tabular}{|c|c|}
\hline \multicolumn{2}{|l|}{ Forecast: INFF } \\
\hline \multicolumn{2}{|l|}{ Actual: INF } \\
\hline \multicolumn{2}{|c|}{ Forecast sample: 2020M01 2020M05 } \\
\hline Included observations: 5 & \\
\hline Root Mean Squared Error & 0.086539 \\
\hline Mean Absolute Error & 0.080761 \\
\hline Mean Abs. Percent Error & 0.659769 \\
\hline Theil Inequality Coefficient & 0.003539 \\
\hline Bias Proportion & 0.870928 \\
\hline Variance Proportion & 0.069158 \\
\hline Covariance Proportion & 0.059913 \\
\hline Theil U2 Coefficient & 0.972427 \\
\hline Symmetric MAPE & 0.662291 \\
\hline
\end{tabular}

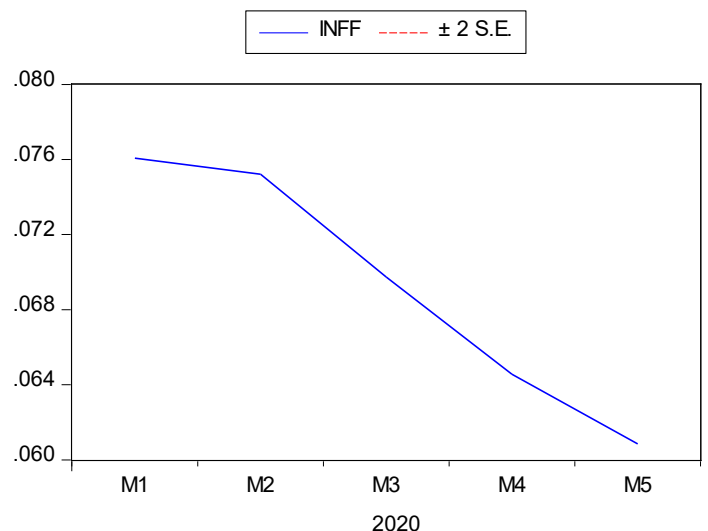

_ Forecast of Variance

Figure 4: Modified Sample Static forecast

The return on inflation is also stable and shows that volatility slows towards end of the month, we can see a downward spiral, which means price reaction to economic crisis led to lower production, lower wages, decreased demand, and still lower prices.

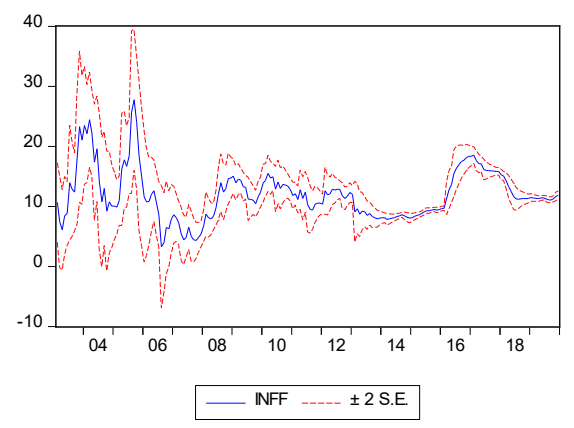

\begin{tabular}{|ll|}
\hline \multicolumn{2}{|l|}{ Forecast: INFF } \\
Actual: INF \\
Forecast sample: 2003M01 2019M12 \\
Adjusted sample: 2003M02 2019M12 \\
Included observations: 203 \\
Root Mean Squared Error & 1.652268 \\
Mean Absolute Error & 1.008348 \\
Mean Abs. Percent Error & 9.160334 \\
Theil Inequality Coefficient & 0.065068 \\
$\quad$ Bias Proportion & 0.000002 \\
Variance Proportion & 0.005262 \\
Covariance Proportion & 0.994736 \\
Theil U2 Coefficient & 0.974473 \\
Symmetric MAPE & 8.663622 \\
\hline
\end{tabular}

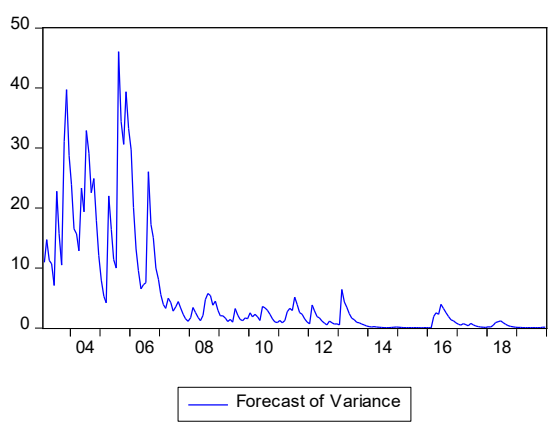

Figure 5: Initial Sample Static forecast $(\mathrm{GARCH})$ 

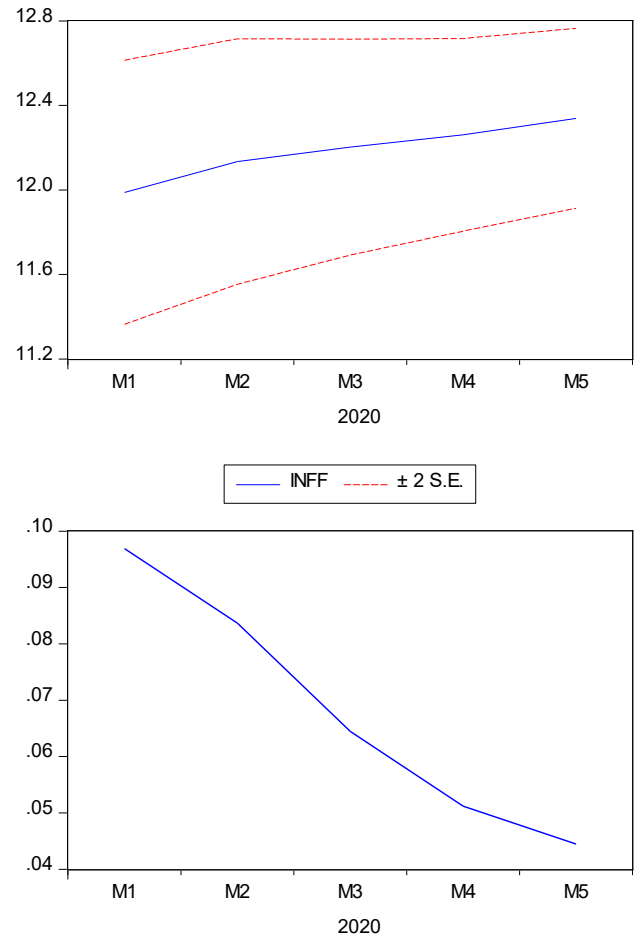

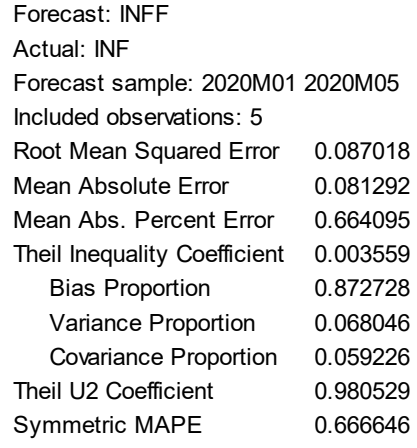

Figure 6: Modified Sample Static forecast

The return on inflation is also stable and shows that volatility slows towards end of the month, we can see a downward spiral, which means price reaction to economic crisis led to lower production, lower wages, decreased demand, and still lower prices.

Table 6: summary of the results using students t distribution.

\begin{tabular}{|l|l|l|l|l|l|l|l|}
\hline & $\begin{array}{l}\text { "Akaike } \\
\text { Information } \\
\text { Criterion" } \\
\text { (AIC) }\end{array}$ & $\begin{array}{l}\text { "Schwarz } \\
\text { Criterion" } \\
\text { (SIC) }\end{array}$ & $\begin{array}{l}\text { "Hannan- } \\
\text { Quinn" } \\
\text { (H-Q) }\end{array}$ & $\begin{array}{l}\text { Root } \\
\text { Mean } \\
\text { Square } \\
\text { Error } \\
\text { (RMSE) }\end{array}$ & $\begin{array}{l}\text { Mean } \\
\text { Absolute } \\
\text { Error } \\
\text { (MAE) }\end{array}$ & $\begin{array}{l}\text { Mean } \\
\text { Absolute } \\
\text { Percentage } \\
\text { Error } \\
\text { (MAPE) }\end{array}$ & $\begin{array}{l}\text { Inequality } \\
\text { Coefficient }\end{array}$ \\
\hline GARCH & $\mathbf{2 . 6 5 2 2 5 0 0}$ & $\mathbf{2 . 7 4 8 7 7 6}$ & $\mathbf{2 . 6 9 1 4 2 9}$ & $\mathbf{1 . 6 5 2 2 6 8}$ & $\mathbf{1 . 0 0 8 3 4 8}$ & $\mathbf{9 . 1 6 0 3 3 4}$ & $\mathbf{0 . 6 5 6 8}$ \\
\hline TGARCH & $\mathbf{2 . 5 9 0 4 3 8}$ & $\mathbf{2 . 7 0 2 7 5 9}$ & $\mathbf{2 . 6 3 5 8 5 5}$ & $\mathbf{1 . 6 5 2 5 2 6}$ & $\mathbf{1 . 0 0 8 4 1 3}$ & $\mathbf{9 . 1 6 0 9 2 2}$ & $\mathbf{0 . 0 6 5 0 7 5}$ \\
\hline
\end{tabular}

Sample: January, 2003 to May, 2020

The Nigeria Inflation Rate has a great difference between its highest and lowest returns. There is high increase in the standard deviation which indicates a high level of variations in the Nigeria Inflation Rate. positive skewness is evident, which implies that the right tail is mostly extreme, which is an indication that Nigeria Inflation Rate has non-symmetric returns. The inflation rate is leptokurtic or fat- 
tailed. The inflation rate series conform with normal distribution and displayed positive skewness as seen in Figure 1 above.

The results in table 2 to 5 give the result of each of the model tested, that is GARCH $(1,1)$ and TGARCH $(1,1)$ using student $t$ distribution and normal distribution respectively. This is being carried out using the ARCH test. To do this, an AR model was carried out and the residual was tested using the $\mathrm{ARCH}$ test. The $f$-statistics and $\mathrm{O}^{*} R^{2}$ Indicates the presence of autoregressive conditional heteroscedasticity (ARCH) in the data. This justified the use of the GARCH and TGARCH models. These findings in table 2 establish the presence of time-varying conditional volatility of returns of the inflation rate. This result also indicates that the persistence of volatility shocks, as represented by the sum of the ARCH and GARCH parameters $\left(b_{1}+c_{1}\right)$, is large. It denotes that the effect of today's shock remains in the forecast of variance for many periods in the future.

We also performed the initial sample static forecast and modified sample static forecast for both the GARCH and TGARCH models using student $t$ distribution because of the inadequacy of the normal distribution. Table 6, explained the various model's selection criteria.

\section{Conclusion}

Two different models were considered in this paperwork. Nigeria's inflation rate was modeled by applying the Generalized Autoregressive Conditional Heteroscedasticity (GARCH) models. Both symmetric and asymmetric models that capture the most common stylized facts about the rate of inflation in Nigeria such as volatility clustering and leverage effects were studied. These models are GARCH $(1,1)$ and Threshold GARCH $(1,1)$. The first model implies the symmetric effect of past shocks whereas the TGARCH model allows capturing of asymmetric effects.

In comparing the two models using AIC, SIC, H-Q, RMSE, MAE, MAPE, Theils Inequality Coefficient, it was discovered that TGARCH $(1,1)$ model performed better than GARCH $(1,1)$ models because it has the least AIC of 2.590438, SIC of 2.702759 and H-Q of 2.635855 respectively. And it also has the highest Theils Inequality Coefficient of 0.065075 .

The return on inflation is also stable and shows that volatility slows towards end of the month, we can see a downward spiral, which means price reaction to economic crisis led to lower production, lower wages, decreased demand, and still lower prices.

This research can be challenging for further exploration. Many other areas can be looked into, like combining GARCH with TGARCH to form a model that is the GARCH-TGARCH model and compared the result with GARCH and TGARCH models to see the efficiency of the combine symmetric and asymmetric model on the set of data. This area can be explored in future research to get a better result. 


\section{Acknowledgement}

We hereby acknowledged JOSMA, TETFUND and our respective institutions for giving us the opportunity to express our academic intellects in this regard.

\section{References}

Alnajjar D, (2016). Modelling and Estimation of Volatility Using ARCH/GARCH Models in Jordan Stock Market. Asian Journal of Finance and Accounting, 8(1):152.

Bollerslev.T, (1990). Modelling the Coherence in Short-Run Nominal Exchange Rate: A Multivariate Generalized ARCH model. The Review of Economics and Statistics, 72(3):498-505.

Chikobvu, D., and T. Makoni, (2019). Statistical modelling of Zimbabwe's international tourist arrivals using both symmetric and asymmetric volatility models. Journal of Economic and Financial Sciences, 12(1), a426. https:// doi.org/10.4102/jef.v12i1.426

Fasanya I.O., and O.B Adekoya, (2017). Modelling Inflation Rate Volatility in Nigeria with Structural Breaks, Central Bank Nigeria Journal of Applied Statistics, 8(1):175-193.

Moradi M.A, (2006). A GARCH Model of Inflation and Inflation Uncertainty in Iran. The Quarterly Journal of the Economic Research 6(1):121-148.

Morawakage, P.S., and P.D. Nimal. (2015). Equity Market Volatility Behaviour in Sri Lankan Context. Kelaniya Journal of Management, University of Kelaniya, 4(2):1-9.

Mulukalapally., S. (2017). Application of GARCH Models to Forecast Financial Volatility of Daily Returns. An Empirical Study on the Indian Stock Market. Asian J. Management, 8(3): 1-9.

Pradipta K.S., and P. Gahan. (2016) Volatility behaviour in Emerging Stock Markets- A GARCH Approach. International Journal of Business Analitics and intelligence, 4(2):21-35.

Samson T.K, Onwukwe C.E and Enang E. I (2020). Modelling Volatility in Nigerian Stock Market: Evidence from Skewed Error Distributions; International Journal of Modern Mathematical Sciences, 18(1): 42-57.

Savadatti P.M, (2018). Sectoral Analysis of Bombay Stock Exchange Application of GARCH Model. International Journal of Management Studies, 2(7):40.

Shveta S., and Teena, (2019). Modelling the Volatility of Banking Sectors of National Stock Exchange. Indian Journal of Economics and Development, 7(3):1-9.

Timothy Kayode Samson, Ekaette Inyang Enang and Christian Elendu Onwukwe (2020). Estimating the Parameters of GARCH Models and Its Extension: Comparison between Gaussian and nonGaussian Innovation Distributions; Covenant Journal of Physical \& Life Sciences (CJPL), 8(1): $2354-3574$. 